\title{
Distinct molecular signals for nuclear import of the nucleolar snRNA, U3
}

\author{
Susan J. Baserga, ${ }^{1}$ Maureen Gilmore-Hebert, ${ }^{2}$ and Xiangdong W. Yang \\ Howard Hughes Medical Institute and Departments of Molecular Biophysics and Biochemistry and ${ }^{2}$ Therapeutic Radiology, \\ Yale University School of Medicine, New Haven, Connecticut 06510 USA
}

\begin{abstract}
Export to the cytoplasm of U3 RNA transcribed from a rat U3 gene injected into the nucleus of Xenopus oocytes indicates that the biogenesis of U3 RNA, like that of the previously studied Sm-precipitable nucleoplasmic snRNAs (U1, U2, U4, and U5), includes a cytoplasmic phase. The regulation of import of the U3 snRNA into the nucleus has been analyzed by injection of synthetic human U3 transcripts into the cytoplasm of Xenopus oocytes. Binding of the major autoantigenic protein of the U3 snRNP, fibrillarin, and cap trimethylation can occur in the cytoplasm, but neither are required for import. The 3 '-terminal 13 nucleotides are required for optimal import and cap trimethylation and participate in a phylogenetically conserved U3 structural element, a short 3 '-terminal stem. An artificial construct containing the 3 '-terminal 13 nucleotides, including the 3 '-terminal stem, but only 56 nucleotides of the 217 nucleotides in U3, appears to be sufficient for import. The presence of the 3 '-terminal stem in all snRNAs known to be imported suggests that it might be a universal element required for nuclear import.
\end{abstract}

[Key Words: Nuclear import; Xenopus oocytes; U3 snRNA; fibrillarin; trimethyl guanosine cap]

Received November 5, 1991; revised version accepted March 20, 1992.

All RNA polymerase II transcripts whose biogenesis has been well-studied, including the spliceosomal small nuclear RNAs (snRNAs) U1, U2, U4, and U5 and mRNA, exit the nucleus at some stage in their maturation /for review, see Parry et al. 1989; Lamond 1990; Andersen and Zieve 1991; Dingwall 1991; Goldfarb and Michaud 1991; Nigg et al. 1991). These RNAs acquire a 7-methyl guanosine cap cotranscriptionally, which acts as one of the signals for nuclear export (Hamm and Mattaj 1990). After export, mRNA remains in the cytoplasm to be translated into protein. In contrast, the spliceosomal snRNAs are reimported into the nucleus as ribonucleoproteins, where they participate in mRNA splicing.

DeRobertis et al. (1982) first showed that the human spliceosomal snRNAs (U1, U2, U4, U5, and U6) injected into the cytoplasm of Xenopus oocytes became concentrated in the nucleus and that binding of the common ribonucleoprotein polypeptides, called the Sm proteins, could occur in the cytoplasm. Subsequently, the binding of the Sm proteins was found to be required for import of Xenopus U1 and U2 (Mattaj and DeRobertis 1985; Mattaj 1986; Hamm et al. 1990) and of human Ul (Fischer and Lührmann 1990) by injection of mutant RNAs lacking the Sm-binding site into Xenopus oocytes. The binding of the Sm proteins is also required for hypermethylation of the 7-methyl guanosine cap to 2,2,7-trimethyl guanosine (TMG) (Mattaj 1986; Hamm et al. 1990), which occurs for each of the spliceosomal snRNAs (U1,

${ }^{1}$ Corresponding author.
U2, U4, and U5) in the cytoplasm. It has been hypothesized that a bipartite signal, consisting of both the TMG cap and bound $\mathrm{Sm}$ proteins, is necessary for import of Xenopus U1 and U2 and human U1 snRNAs (Hamm et al. 1990; Fischer and Lührmann 1990). However, further investigation (Konings and Mattaj 1987; Neuman de Vegvar and Dahlberg 1990) suggests that this bipartite signal functions only on snRNAs with the correct structure. In contrast to the U1 and U2 snRNAs, the chicken $\mathrm{U} 4$ and Xenopus U5 snRNAs bind the Sm proteins in the cytoplasm but do not require a trimethylated cap structure to be imported (Fischer et al. 1991). These data suggest that there are at least two different pathways of import for trimethyl cap-containing snRNAs.

Another abundant vertebrate snRNA transcribed by RNA polymerase II (for review, see Dahlberg and Lund 19881, the U3 snRNA, participates in rRNA processing in the nucleolus (Kass et al. 1990; Savino and Gerbi 1990). It belongs to a group of three nucleolar snRNAs (U3, U8, and U13) that share sequence similarities (Tyc and Steitz 1989|, including the trimethyl cap, and assemble into particles immunoprecipitable by anti-fibrillarin $(\alpha \mathrm{Fb})$ but not by anti-Sm $(\alpha \mathrm{Sm})$ autoantibodies. We refer to this group of nucleolar small nuclear ribonucleoproteins (snRNPs) as the Fb snRNPs. The U3 snRNP consists of one 217-nucleotide-long RNA and six proteins $(74,59,34,30,13$, and $12.5 \mathrm{kD}$; Parker and Steitz 1987). A sequence required for binding of its major autoantigenic protein, the 34-kD Fb, has been defined (Baserga et al. 1991). Otherwise, little is known about the biogenesis of the U3 snRNP. 
Here, we study the biogenesis of the mammalian U3 snRNP in Xenopus oocytes. We show that like the polymerase II-transcribed spliceosomal snRNAs (U1, U2, U4, and U5) the U3 snRNA is exported to the cytoplasm and reimported into the nucleus. We ask, by analogy to the binding of the Sm proteins to the spliceosomal snRNAs, whether binding of the common protein $\mathrm{Fb}$ or cap trimethylation is required for import of the U3 snRNA. We identify a novel structural motif, the 3 '-terminal stem, which is required both for import and cap trimethylation of the U3 snRNA. A 56-nucleotide RNA containing the 3 '-terminal stem appears to be sufficient for import. Inspection of all imported snRNAs studied so far reveals that a similar structural motif may be common among them.

\section{Results}

Export of the U3 snRNA from the nucleus to the cytoplasm

It was first necessary to establish whether the U3 snRNA, like the spliceosomal snRNAs, is exported to the cytoplasm and undergoes cap hypermethylation there to yield a trimethylated snRNA (2,2,7-TMG). A rat U3 gene cloned into pUC13 (called - 375 U3D; Stroke and Weiner 1985; Ach and Weiner 1991) was injected into the nucleus of Xenopus oocytes, and transcription was monitored by coinjection of [ ${ }^{32} \mathrm{P} \mid \mathrm{GTP}$. RNA was harvested from the nucleus and cytoplasm and compared with total RNA and with RNA from oocytes injected only with $\left[{ }^{32} \mathrm{P}\right] \mathrm{GTP}$. Time points at 10 and $30 \mathrm{~min}, 1,3$, and $18 \mathrm{hr}$ were taken. Figure $1 \mathrm{~A}$ shows the results with the 18-hr time point. The U3 transcript appears in total, cytoplasmic, and nuclear RNA (lanes 2-4). The level of transcription from this plasmid is comparable to that of the endogenous 5S RNA. The ratios of 5S RNA to U3 transcript are similar in both the total and cytoplasmic lanes. U3 is not seen in oocytes injected with $\left[{ }^{32}\right]$ GTP only (lane 1). More U3 transcript appears in the nuclear lanes than in the cytoplasmic lanes at all time points (data not shown), as would be expected. As shown in the subsequent figures, our fixation and dissection procedure cleanly separates cytoplasmic and nuclear RNAs. The appearance of $\mathrm{U} 3$ in the cytoplasmic fraction therefore allows us to conclude that U3 is exported to the cytoplasm after transcription.

To investigate whether U3 snRNA can undergo cap trimethylation in the cytoplasm of Xenopus oocytes, synthetic ${ }^{32} \mathrm{P}$-labeled GpppG-capped human U3 snRNA was injected into the cytoplasm of whole Xenopus oocytes or into enucleated oocytes. Soon after injection $(0 \mathrm{hr})$ and at $18 \mathrm{hr}$, RNA was purified and trimethylation was assessed by immunoprecipitation with anti-trimethyl guanosine ( $\alpha \mathrm{TMG}$ ) antibodies. As shown in Figure 1B, lanes 1 and 3, newly injected GpppG-capped U3 RNA is not immunoprecipitated by $\alpha$ TMG antibodies, whereas U3 RNA that has been incubated in either whole oocytes (lane 2) or in enucleated oocytes (lane 4) for $18 \mathrm{hr}$ becomes immunoprecipitable. Thus, the U3 cap can become trimethylated in the cytoplasm.

Injected U3 RNA can also bind Fb in the cytoplasm, as shown in Figure 1C. U3 RNA was injected into either enucleated or whole oocytes and then assayed for $\mathrm{Fb}$ binding by immunoprecipitation with $\alpha \mathrm{Fb}$ antibodies immediately after injection $(0 \mathrm{hr})$ or at $2 \mathrm{hr}$. The amount of $\mathrm{U} 3$ bound to $\mathrm{Fb}$ at $0 \mathrm{hr}$ reflects background binding and is proportional to the quantity of RNA injected. Figure $\mathrm{IC}$, lanes 2 and 4 , reveals that the binding of $\mathrm{Fb}$ to $\mathrm{U} 3$ in enucleated oocytes is about equivalent to that in whole oocytes (lanes 6,8). The percentage of RNA immunoprecipitable with $\alpha \mathrm{Fb}$ antibodies with respect to the RNA in the supernatant was calculated; there is approximately threefold more U3 RNA immunoprecipitable in the enucleated oocytes than in the whole oocytes.

To ensure that the binding of $\mathrm{Fb}$ to $\mathrm{U} 3$ was specific, we took advantage of our previous demonstration that an intact box $\mathrm{C}$ sequence (see Fig. 3, below) is necessary for Fb binding in HeLa cell extract (Baserga et al. 1991). Equal amounts (cf. the 0-hr time points for each; lanes 6,10 ) of wild-type U3 and a U3 with a point mutation in box C (U3 G159A), which severely reduces binding of human $\mathrm{Fb}$ in vitro, were injected, and the resulting extracts were immunoprecipitated with $\alpha \mathrm{Fb}$ antibodies. The percentage of RNA immunoprecipitable with $\alpha \mathrm{Fb}$ antibodies with respect to the RNA in the supernatant was calculated; there is approximately eightfold less U3 G159A RNA immunoprecipitable when compared with wild-type $\mathrm{U} 3$. This suggests that box $\mathrm{C}$ also directs $\mathrm{Fb}$ binding in vivo in Xenopus oocytes.

\section{Binding of the major autoantigenic protein $\mathrm{Fb}$ is not necessary for U3 snRNA import}

Because $\mathrm{Fb}$ can bind to U3 snRNA in the cytoplasm, we asked, by analogy to the Sm proteins, whether Fb binding was necessary for nuclear import. Increasing amounts of purifed $\alpha \mathrm{Fb}$ monoclonal antibody (Reimer et al. 1987) were coinjected with U3 snRNA into the cytoplasm of Xenopus oocytes. Even at antibody concentrations as high as $0.8 \mathrm{mg} / \mathrm{ml}$, no inhibition of nuclear transport is seen after an 18-hr incubation (Fig. 2, lanes 7-10). This amount of antibody $(50 \mathrm{nl}$ of $0.8 \mathrm{mg} / \mathrm{ml})$ is sufficient to bind all of the available U3 snRNPs in a Xenopus oocyte (data not shown). We conclude that although $\mathrm{Fb}$ can bind U3 snRNA in the cytoplasm its binding is not required for import. This conclusion is confirmed in experiments described below assessing the import of $\mathrm{U} 3$ mutated in box C.

\section{Requirements for U3 snRNA import} from the cytoplasm to the nucleus

Modifications of the U3 snRNA were made either by truncation or by site-directed mutagenesis to establish what regions or structures are necessary for import and cap trimethylation. The sequence and structure of $\mathrm{U} 3$ snRNA is shown in Figure 3. U3 snRNAs truncated at 
B

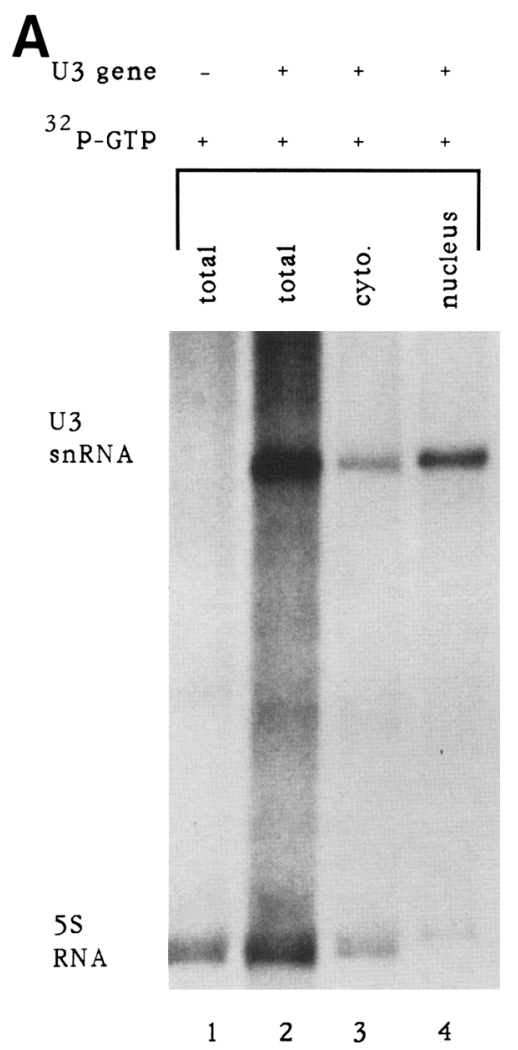

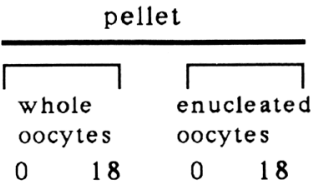

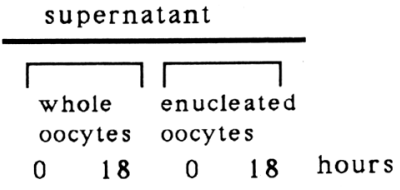

U3
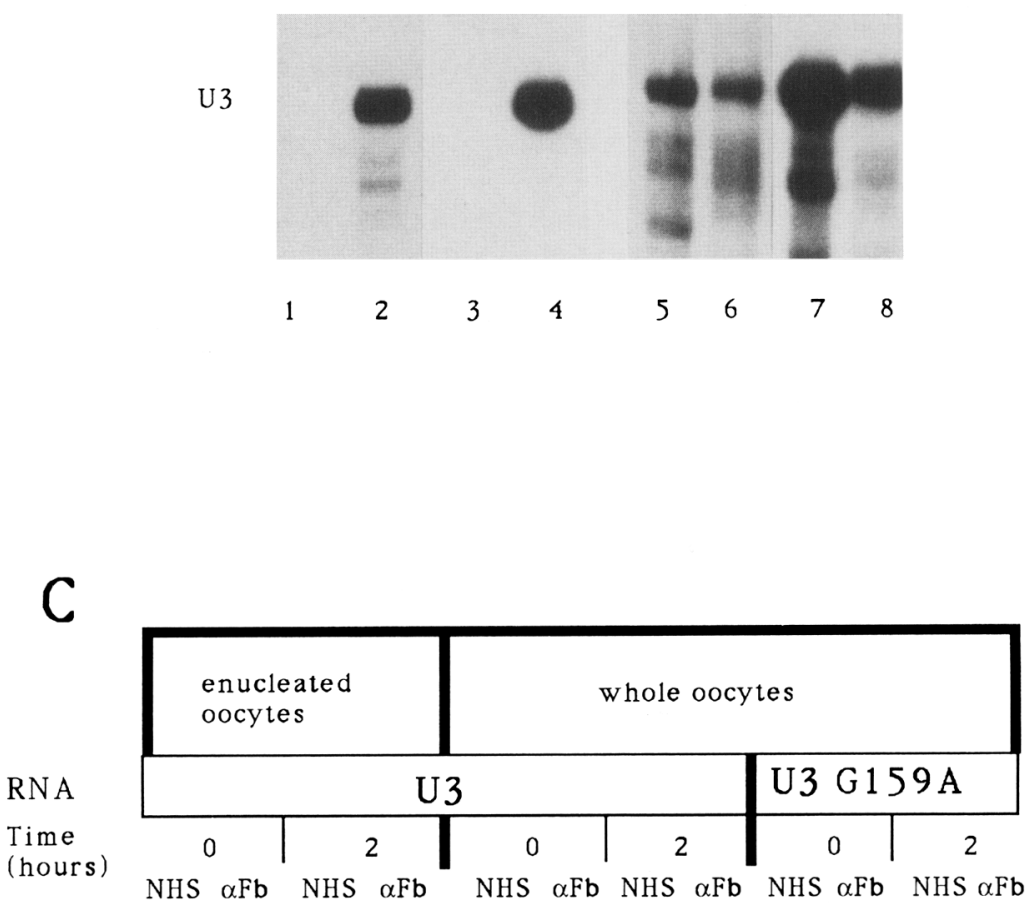

$\mathrm{NHS} \alpha \mathrm{Fb}$ NHS $\alpha \mathrm{Fb}$ NHS $\alpha \mathrm{Fb}-\mathrm{NHS} \alpha \mathrm{Fb}$

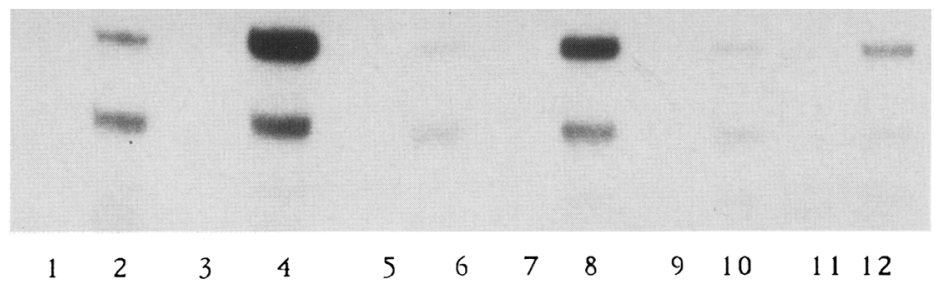

Figure 1. (A) U3 snRNA exits the nucleus after transcription. Xenopus oocytes were coinjected with the rat U3 gene / $-375 \mathrm{U} 3 \mathrm{D}$ in pUC13) and $\left[\alpha{ }^{32} \mathrm{P}\right] \mathrm{GTP}$ or with $\left[\alpha^{-32} \mathrm{P}\right] \mathrm{GTP}$ alone. After $18 \mathrm{hr}$, total (10 oocytes) or nuclear and cytoplasmic (10 oocytes) RNAs were analyzed on an $8 \%$ denaturing polyacrylamide gel. (B) U3 snRNA undergoes $5^{\prime}$ cap trimethylation in the cytoplasm of Xenopus oocytes. In vitro-transcribed GpppG-capped U3 snRNA was injected into the cytoplasm of whole or enucleated Xenopus oocytes. RNA was harvested immediately after injection (10 oocytes) or at $18 \mathrm{hr}$ (10 oocytes) and assayed for trimethylation by immunoprecipitation with $\alpha$ TMG antibodies. Pellet and supernatant were analyzed on an $8 \%$ denaturing polyacrylamide gel. Some RNA degradation (lanes 5-8) occurs after isolation of the total RNA during the immunoprecipitation. (C) U3 snRNA can bind Fb in the cytoplasm of Xenopus oocytes, and such binding is affected by a single point mutation in box C (G159A). In vitro-transcribed U3 RNA was injected into either whole or enucleated oocytes. U3G159A was injected into whole oocytes. Oocyte extracts were made either immediately after injection (10 oocytes) or at $2 \mathrm{hr}$ ( 10 oocytes). Binding of $\mathrm{Fb}$ was assayed by immunoprecipitation with $\alpha \mathrm{Fb}$ autoantibodies and was compared with immunoprecipitation with normal human serum (NHS). RNA was analyzed on an $8 \%$ denaturing polyacrylamide gel. These results were quantitated on a Vision 200 densitometer.

the $3^{\prime}$ end were synthesized by in vitro transcription of the U3 plasmid or replicative form (RF) DNA that had been digested with BstUI (transcript of 204 nucleotides), Fnu4HI (transcript of 138 nucleotides) or DdeI (transcript of 104 nucleotides), as indicated in Figure 3. Mutations were also introduced into boxes $\mathrm{B}, \mathrm{C}$, and $\mathrm{D}$; these regions have been deduced to be involved in protein binding to U3 snRNA (Parker and Steitz 1987) and are highly conserved from yeast to human U3 snRNAs (Parker and Steitz 1987; Jeppesen et al. 1988; Porter et al. 1988; summarized in Tyc and Steitz 1989). Because simple deletion of the box B, C, or D sequences would be expected to alter the structuure of the RNA drastically, substitution/ deletion of each of these regions was designed instead. They are called $\Delta \mathrm{B}, \Delta \mathrm{C}$, and $\Delta \mathrm{D}$ and are indicated in Figure $3(\beta B=$ nucleotides $106-114 ; \Delta C=$ nucleotides 


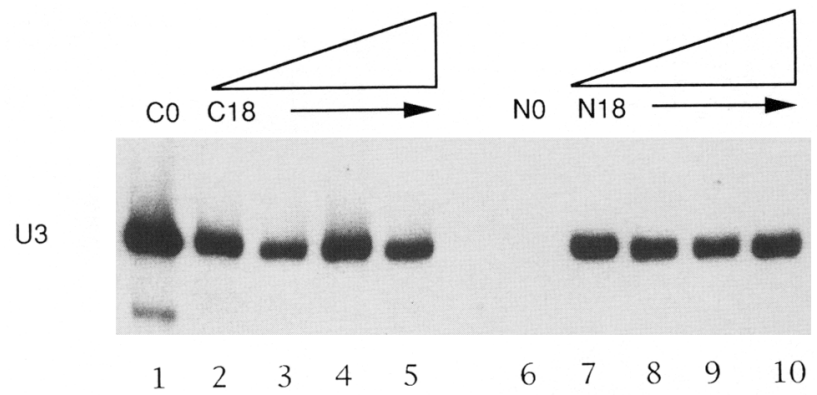

Figure 2. Prior injection of $\alpha \mathrm{Fb}$ antibody does not affect $\mathrm{U} 3$ RNA nuclear import. Oocytes were injected with buffer (lanes $1,2,6,7)$ or with increasing concentrations of $\alpha \mathrm{Fb}$ antibody (lanes 3-5, 8-10) $1 \mathrm{hr}$ before injection with in vitro-transcribed human U3 RNA. Oocytes were fixed and dissected into cytoplasm $(\mathrm{C})$ and nucleus $(\mathrm{N})$, either immediately after injection $\{\mathrm{C} 0, \mathrm{~N} 0\}$ or after $18 \mathrm{hr}(\mathrm{C} 18, \mathrm{~N} 18)$. The maximum concentration of $\alpha \mathrm{Fb}$ antibody injected is $0.8 \mathrm{mg} / \mathrm{ml}$ (lanes 5,10 ). Lanes 4 and 9 represent a $1: 10$ dilution; lanes 3 and 8 represent a $1: 100$ dilution of the concentrated antibody.

158-166; $\Delta \mathrm{D}=$ nucleotides 207-212). Finally, mutations predicted to perturb the U3 RNA secondary structure were introduced into the 5 terminal nucleotides of U3 (nucleotides 213-217). These mutations affect the 3 '-terminal stem and are shown in the boxed sequence identified as the stem mutation in Figure 3. Compensatory mutations were also made in the U3 RNA (nucleotides 75-79) to restore base-pairing. These are indicated in the boxed sequences identified as the stem mutation suppressor in Figure 3.

Figure 4 shows that injected wild-type U3 snRNA is both imported into the nucleus (Fig. 4A, lanes 1-4) and cap trimethylated (Fig. 4B, lanes 1,2). In contrast, U3 BstUI (104 nucleotides; see Fig. 3), which is truncated only 13 nucleotides from the $3^{\prime}$ end, is neither imported (Fig. 4B, lanes 5-8) nor trimethylated (Fig. 4C, lanes 3,4). The absence of U3 BstUI RNA in the nucleus is not the result of preferential increased nuclear degradation of this RNA because the overall stability of the wild-type and truncated RNAs is very similar. Two other truncated U3 snRNAs, U3 Fnu4HI and U3 DdeI, which are even shorter (see Fig. 3), exhibit similar behavior (Fig. 4D, and data not shown). Quantitatively, import of the truncated U3 snRNAs (U3 BstUI, U3 Fnu4HI, and U3 DdeI) is $\sim 100$-fold less than full-length U3 snRNA (Fig. $4 \mathrm{D}$ |. These experiments suggest that a sequence or structure in the U3 snRNA itself is necessary for import. Deletion of 13 nucleotides from the $3^{\prime}$ end might affect either direct binding of a protein to box $\mathrm{D}$ or a particular structure required for import.

Figure 4C compares the import into the nucleus of three substituted/deleted U3 snRNAs with that of wildtype after injection into the cytoplasm of Xenopus oocytes. Surprisingly, $\Delta \mathrm{B}, \Delta \mathrm{C}$, and $\Delta \mathrm{D}$ are all imported to a significant extent (Fig. 4B, lanes 5-16). Quantitation of the results from Figure $4, A$ and $B$, and other experiments indicates that U3 snRNA import is lowered only two- to threefold by the substitution/deletion mutations (Fig. 4D). We therefore consider that the substituted/deleted U3 snRNAs are subject to active, albeit somewhat impaired, import compared with the truncated RNAs, whose import is reduced to background levels (Fig. 4D).

Because we showed previously that a single-base substitution in box $\mathrm{C}$ abolishes $\mathrm{Fb}$ binding in vitro (Baserga et al. 1991) and now in vivo (Fig. 1C), the results with U3 $\Delta \mathrm{C}$ (Fig. 4, lanes 9-12) argue further that $\mathrm{Fb}$ binding is not required for import. Additional experiments (data not shown) confirmed that several different point mutations in box $\mathrm{C}$, which affect $\mathrm{Fb}$ binding in vitro, also have no effect on import or cap trimethylation.

Truncation of U3 snRNA by as little as 13 nucleotides abolishes import (100-fold less than wild type). Within these 13 nucleotides are two phylogenetically conserved motifs: (1) the box D sequence, and (2) the $3^{\prime}$-terminal stem (Fig. 3; Parker and Steitz 1987; Jeppesen et al. 1988). Because substitution of the box $D$ sequence reduces import only about threefold $(\Delta \mathrm{D}$ in Fig. $4 \mathrm{D})$ and cap tri-

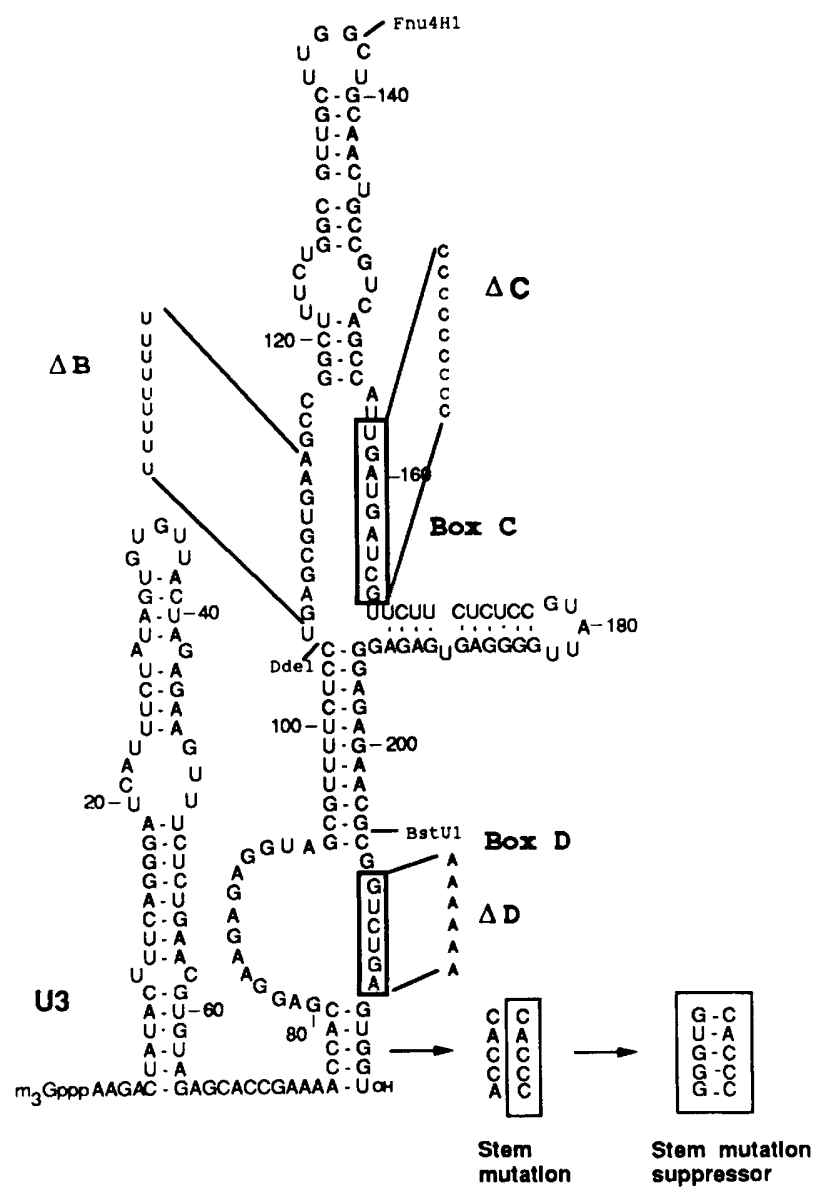

Figure 3. Sequence and structure of human U3 snRNA (Parker and Steitz 1987). Indicated are restriction sites used to cleave either plasmid or M13 RF DNA to make truncated U3 RNA transcripts (BstUI, Fnu4HI, DdeI). The substitution/deletion mutations of boxes $B, C$, and $D$ are indicated $(\Delta B, \Delta C, \Delta D)$. The stem mutation (nucleotides 213-217) and stem mutation suppressor are indicated. 
Figure 4. (A) U3 snRNA import from the cytoplasm to the nucleus of Xenopus oocytes is regulated. In vitro-transcribed U3 RNA or U3 RNA truncated at the BstUI site (see Fig. 3) was injected into the cytoplasm of Xenopus oocytes. Oocytes were fixed and dissected into cytoplasm $(\mathrm{C})$ and nucleus $(\mathrm{N})$, either immediately after injection $(\mathrm{CO}, \mathrm{NO})$ or after 18 $\mathrm{hr}(\mathrm{C} 18, \mathrm{~N} 18)$. RNA from each compartment was analyzed on an $8 \%$ denaturing polyacrylamide gel. (B) Truncation of U3 snRNA abolishes $5^{\prime}$ cap trimethylation. In vitro-transcribed U3 RNA or U3 RNA truncated at the $B s t$ UI site was injected into Xenopus oocytes. Total RNA was harvested either immediately after injection or at $18 \mathrm{hr}$. Equal amounts of ${ }^{32} \mathrm{P}$-labeled RNA were immunoprecipitated with $\alpha$ TMG antibodies and analyzed on an $8 \%$ denaturing polyacrylamide gel. (C) Substitution/deletion of three conserved regions in U3 snRNA has only a small effect on import. In vitro-transcribed $\mathrm{U} 3 \mathrm{RNA}$ and three substitution/deletions of $\mathrm{U} 3\langle\Delta \mathrm{B}, \Delta \mathrm{C}, \Delta \mathrm{D}$; Fig. 3) were injected into the cytoplasm of Xenopus oocytes. Oocytes were fixed and dissected into cytoplasm $(\mathrm{C})$ and nucleus $(\mathrm{N})$, either immediately after injection $(\mathrm{CO}, \mathrm{NO})$ or after 18 $\mathrm{hr}(\mathrm{C} 18, \mathrm{~N} 18)$. RNA from each compartment was analyzed on an $8 \%$ denaturing polyacrylamide gel. U3 $\Delta \mathrm{C}$ (lanes 9-12) and U3 $\Delta \mathrm{D}$ (lanes 13-16) are from the same experiment as $\mathrm{U} 3$ and $\mathrm{U} 3 \Delta \mathrm{B}$ but were exposed for one-fifth the time. $(D)$ Quantitation of import of U3 RNA, three truncated U3 RNAs (U3 BstUI, U3 Fnu4HI, and U3 DdeI; Fig. 3), and three substituted/deleted U3 RNAs $(\Delta \mathrm{B}, \Delta \mathrm{C}, \Delta \mathrm{D}$; Fig. 3). The experiments in $A$ and $C$, as well as others, were quantitated on a Molecular Dynamics PhosphorImager. The percent import is calculated as N18/N18+C18. U3 snRNA import is set at $100 \%$. Each bar represents the average of two experiments. In two experiments, the U3 $\Delta \mathrm{D}$ was imported at $15 \%(C$, lanes $13-16$ ) or $52 \%$, to make an average of $34 \%$. This has been confirmed in a third trial.

methylation to about the same extent (data not shown), we next investigated whether nuclear import and cap trimethylation were sensitive to alterations in RNA structure in the $3^{\prime}$-terminal stem. Mutations were made that abolished the base-pairing (stem mutation; Fig. 3); base-pairing was then reestablished by compensatory mutations in the paired strand (stem suppressor mutation; Fig. 3). As shown in Figure 5A, absence of the 3'. terminal stem greatly reduces (4- to 10 -fold) import when compared with wild type (lanes $4,5,10,11)$. When the stem is reestablished by compensatory mutations in the paired strand, import is restored to wild-type levels (lanes 4,6,10,12). Figure 5B shows similar results with respect to cap trimethylation. U3 snRNAs that lack the 3'-terminal stem are not detectably trimethylated (lanes 2,5 . When the $3^{\prime}$-terminal stem is reestablished, cap trimethylation is restored to wild-type levels (lanes 3,6 ). These results suggest that maintenance of the $3{ }^{\prime}$-terminal stem is necessary for nuclear import and cap trimethylation of the U3 snRNA.
Is the structure at the $3^{\prime}$ end of the U3 RNA sufficient for nuclear import? A fragment of U3 RNA, containing the 3 '-terminal stem and the box $D$ sequence, was constructed (Fig. 6A). When this RNA is injected into Xenopus oocytes, it is highly unstable, and after an 18-hr incubation, only $\sim 1 \%$ remains (Fig. 6 , cf. lanes 5 and 6 ). Surprisingly, in spite of this degradation, some U3 3 '-end fragment RNA was observed to be imported into the nucleus (Fig. 6B, cf. lanes 7 and 8). If percent import is calculated using the $\mathrm{C} 0$ value in the denominator (instead of $\mathrm{C} 18$ because of the extensive degradation), import of the U3 $3^{\prime}$-end fragment is $\sim 60$ - to 100 -fold greater than that of the truncated U3 BstUI RNA (Fig. 4A, and data not shown). These results suggest that this 56-nucleotide fragment of the U3 RNA is sufficient for import, although it appears not to be sufficient for maintenance of RNA stability.

One part of the signal for U1 and U2 snRNA import is the 5' TMG cap. To investigate whether a TMG cap structure is necessary for U3 snRNA import, U3 snRNA 


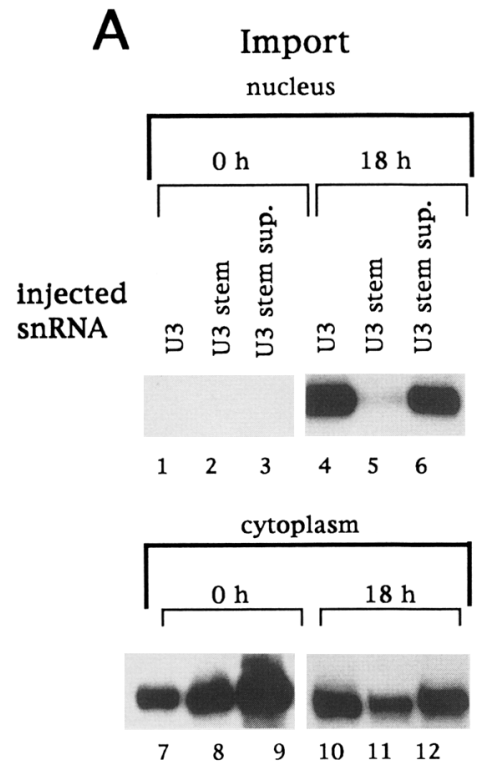

Figure 5. (A) U3 RNA requires a structural motif, the 3 '-terminal stem, for nuclear import. In vitro-transcribed U3 RNA and two RNAs with mutations in the 3 '-terminal stem were injected into Xenopus oocytes. The U3 stem mutation (Fig. 3) abolishes the 3 '-terminal stem; the U3 stem suppressor mutation restores the $3^{\prime}$-terminal stem with compensatory mutations in the base-paired strand (Fig. 3). Oocytes were fixed and dissected into cytoplasm $(\mathrm{C})$ and nucleus $(\mathrm{N})$, either immediately after injection $(\mathrm{CO}, \mathrm{NO})$ or after $18 \mathrm{hr}(\mathrm{C} 18, \mathrm{~N} 18)$. RNA from each compartment was analyzed on an $8 \%$ denaturing polyacrylamide gel. $(B)$ U3 RNA requires a 3 '-terminal stem for TMG cap formation. In vitro-transcribed U3 RNA or two U3 RNAs with mutations in the $3^{\prime}$-terminal stem (stem and stem suppressor; Fig. 3) were injected into Xenopus oocytes. Total RNA was harvested at $18 \mathrm{hr}$. Equal amounts of ${ }^{32} \mathrm{P}$-labeled RNA were immunoprecipitated with $\alpha$ TMG antibodies and analyzed on an $8 \%$ denaturing polyacrylamide gel.

was synthesized with a cap (ApppG) that is not a substrate for trimethylation. The import of U3 containing an ApppG cap was then compared with that of the normal U3 transcript beginning with a GpppG cap, which is a substrate for trimethylation (Fig. 1B; Fischer and Lührmann 1990; Hamm et al. 1990). As controls, import of human U1 snRNA with or without ApppG and import of a truncated U1 snRNA lacking the Sm protein-binding site were examined in parallel. Both the U1 ApppGcapped RNA and the truncated U1 snRNA /GpppG capped) had been shown previously to be deficient in import (Fischer and Lührmann 1990). As shown in Figure 7, the Ul snRNA with a GpppG cap is imported (lane 4), whereas both the Ul snRNA with the ApppG cap (lane 8) and the U1 snRNA minus the Sm protein-binding site (lane 12) are not. The smaller size of the U1 snRNAs at $18 \mathrm{hr}$ is the result of $3^{\prime}$ trimming of the 25 extra nucleotides that are part of this runoff transcript. In contrast, the ApppG-capped U3 snRNA is imported, as well as the GpppG-capped U3 snRNA (Fig. 7, cf. lanes 16 and 20). This demonstrates that although trimethylation of the
U3 snRNA occurs, it is not required for import. We conclude that U3 RNA represents a unique class of import of trimethylated snRNAs that do not bind the Sm proteins and do not require trimethylation for import.

\section{Discussion}

Our studies have outlined the major steps in the biogenesis of the U3 snRNP leading to its accumulation in the nucleus. After transcription by RNA polymerase II, U3 is transported to the cytoplasm, where it can undergo cap trimethylation and bind its major autoantigenic protein $\mathrm{Fb}$. Its subsequent import into the nucleus is dictated largely by a structural motif, the 3 '-terminal stem, and requires neither cap trimethylation nor $\mathrm{Fb}$ binding. $\mathrm{Mu}-$ tation of boxes B, C, and D affects import to a lesser extent. U3 RNA import is therefore different from that described for the spliceosomal snRNAs (Mattaj and DeRobertis 1985; Mattaj 1986; Hamm et al. 1990; Fischer and Lührmann 1990; Fischer et al. 1991) in that it is not dependent on binding of its common autoantigenic protein.

\section{U3 biogenesis includes a cytoplasmic phase}

Whether the biogenesis of the U3 snRNP requires RNA transit through the cytoplasm has been controversial. In particular, steady-state analyses of U3 RNA and Fb during Xenopus oogenesis have localized both exclusively in the nucleus (Caizergues-Ferrer et al. 1991). Unlike the Sm proteins (Forbes et al. 1983; Zeller et al. 1983), Fb is not stockpiled in the Xenopus oocyte cytoplasm. However, as these investigators discuss, $\mathrm{U} 3$ and $\mathrm{Fb}$ synthesis correlates generally with rRNA synthesis. It therefore seems reasonable that $\mathrm{Fb}$ would not be stored because it is complexed with U3 in the U3 RNP, which is participating actively in $\mathrm{rRNA}$ processing in maturing oocytes. Furthermore, U3 snRNA transit through the cytoplasm may be brief and not detectable by Northern blot analysis (Caizergues-Ferrer et al. 1991).

The data we present here and experiments from other laboratories argue that U3 RNA does enter the cytoplasm after transcription. We have observed that U3 snRNA transcribed from a rat U3 gene injected into the nucleus of Xenopus oocytes is found in the cytoplasm (Fig. 1). In pulse-chase analysis of snRNA synthesis in mammalian cells with two different advanced techniques of cell fractionation (Zieve et al. 1988; Feeney et al. 1989), U3 snRNA was also detected in the cytoplasm. Furthermore, because the trimethylation reaction for the spliceosomal snRNAs is believed to be a uniquely cytoplasmic event (Mattaj 1986) and the U3 snRNA cap is trimethylated, U3 snRNA would be expected to undergo this reaction in the cytoplasm. Accordingly, we have shown that the U3 snRNA cap can be trimethylated in the cytoplasm, as is the case for spliceosomal snRNAs (Fig. 1). Finally, Stroke and Weiner (1985) observed that the primary transcript of rat U3 is slightly longer than the snRNA mature size (8-14 nucleotides). The trimming event that matures the $3^{\prime}$ end of the snRNAs is 
A

Figure 6. (A) Diagram of the U3 3 '-end fragment RNA that contains the $3^{\prime}$-terminal stem. This RNA represents a fragment of the U3 RNA, including the box D sequence (boldface box), with these extra nucleotides: a 5' G and a tetraloop of UUCG between U3 nucleotides 101 and 198 (lightface box). (B) The U3 3 ' end fragment of snRNA is sufficient for import. In vitrotranscribed U3 RNA and the U3 $3{ }^{\prime}$-end fragment $\langle A\rangle$ were injected into the cytoplasm of Xenopus oocytes. Oocytes were fixed and dissected into cytoplasm $(C)$ and nucleus $(\mathrm{N})$, either immediately after injection $(\mathrm{C} 0, \mathrm{NO})$ or after $18 \mathrm{hr}(\mathrm{Cl}, \mathrm{N} 18)$. RNA from each compartment was analyzed on an $8 \%$ denaturing polyacrylamide gel.
B

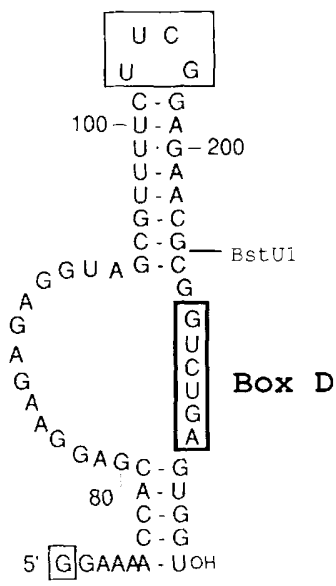

U3 3 ' end fragment

CO $\mathrm{C} 18$ NO N18
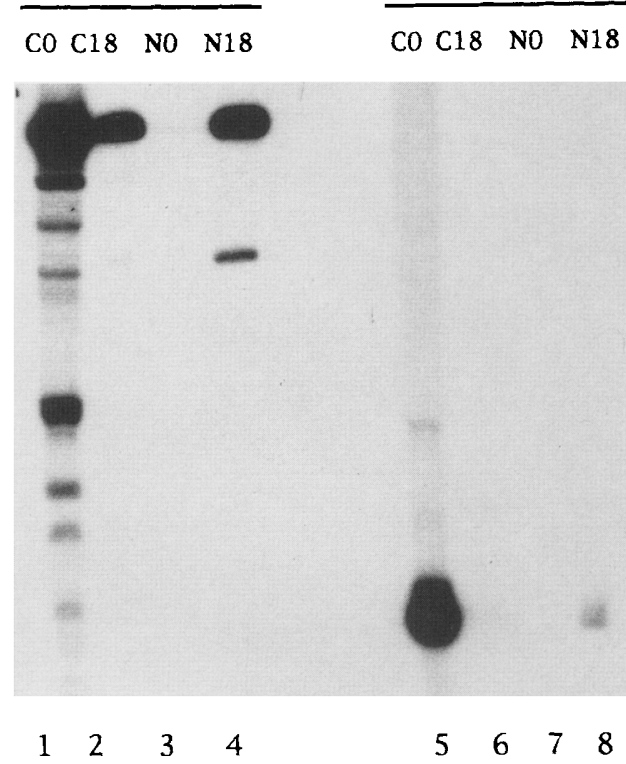

thought to be almost completely cytoplasmic (for review, see Dahlberg and Lund 1988).

The Xenopus oocyte has been used widely to study RNA trafficking of both Xenopus snRNAs and snRNAs from other species because of the ease and precision of microinjection into the nuclear and cytoplasmic compartments. Localization studies of nascent and steadystate snRNAs in mammalian cells using conventional cell fractionation procedures are largely in agreement with data from Xenopus oocytes (Eliceiri 1974; Eliceiri and Sayavedra 1976; Zieve and Penman 1976; Gurney and Eliceiri 1980), as are more recent results (Zieve et al. 1988; Feeney et al. 1989). Taken together, the data argue that snRNP biogenesis in mammalian somatic cells and Xenopus oocytes is similar. Previously, conclusions concerning the biogenesis of the Xenopus, human, and chicken U snRNAs have been drawn from studies in the Xenopus oocyte (see references in introductory section). We anticipate that our findings concerning the human and rat U3 RNA will likewise be generally applicable.

\section{U3 defines a unique class of snRNA import signals}

Previously, it has been shown that import of the splicesomal snRNAs (U1, U2, U4, U5, U6) falls into three distinct groups. Import of $U 1$ and $U 2$ requires both binding of the $\mathrm{Sm}$ proteins and cap trimethylation (Mattaj and DeRobertis 1985; Mattaj 1986; Fischer and Lührmann 1990; Hamm et al. 1990), whereas import of U4 and U5 requires only binding of the $\mathrm{Sm}$ proteins (Fischer et al. 1991). Although U6 is a spliceosomal snRNA, it is transcribed by RNA polymerase III (Kunkel et al. 1986; Das et al. 1988/and acquires a $\gamma$-methyl triphosphate cap (Singh et al. 1990). Unlike the other spliceosomal RNAs but consistent with its transcription by RNA polymerase III and function in the nucleus, U6 does not enter the cytoplasm after transcription (Vankan et al. 1990). If synthetic U6 is injected into the cytoplasm of Xenopus oocytes, however, it is imported in a sequence-dependent manner (Hamm and Mattaj 1989).

Here, we have shown that import of U3 snRNA de-
Figure 7. U3 snRNA is imported in a cap trimethylation-independent manner. In vitro-transcribed Ul snRNA (GpppG-or ApppG-capped), truncated Ul snRNA (Ul minus Sm, 115 nucleotides, and U3 snRNA (GpppG- or ApppG-capped) were injected into the cytoplasm of Xenopus oocytes. Oocytes were fixed and dissected into cytoplasm $\{C)$ and nucleus $(N)$, either immediately after injection $(\mathrm{CO}, \mathrm{NO})$ or after $18 \mathrm{hr}(\mathrm{C} 18, \mathrm{~N} 18)$. RNA from each compartment was analyzed on an $8 \%$ denaturing polyacrylamide gel.

\begin{tabular}{|c|c|c|c|c|}
\hline U1 GpppG & U1 ApppG & $\mathrm{U} 1 \mathrm{~m}$ inus $\mathrm{Sm}$ & U3 GpppG & U3 ApppG \\
\hline
\end{tabular}

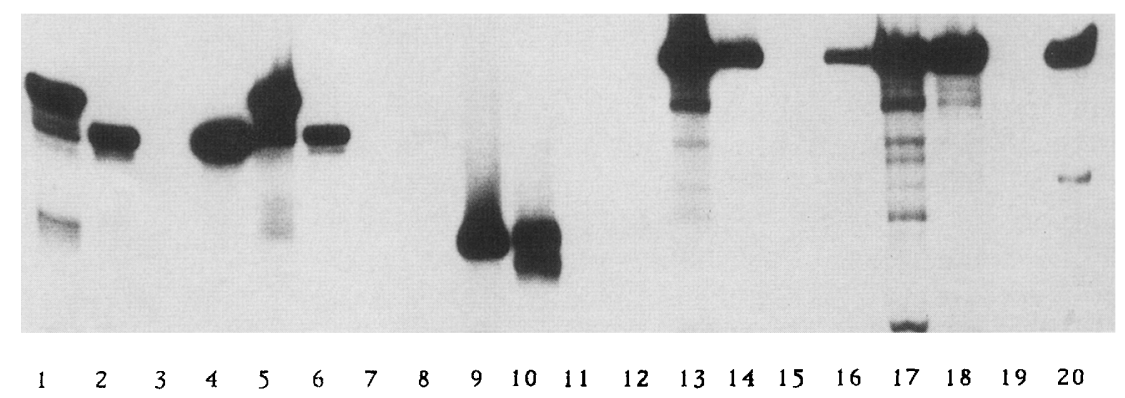


fines a fourth group that is not dependent on binding of the major autoantigenic protein, $\mathrm{Fb}$, or cap trimethylation. Our results are consistent with studies in Saccharomyces cerevisiae (Tollervey et al. 1991), which showed that depletion of the yeast analog of $\mathrm{Fb}$ (NOP1) has no effect on the nuclear or nucleolar localization of U3 snRNA. Michaud and Goldfarb (1992) have also studied import of human U3 snRNA in Xenopus oocytes and found it to be kinetically distinct from U1 snRNA and protein import on the basis of competition assays using free TMG cap or a synthetic peptide analog of the nuclear localization signal of SV40 T antigen [p(Lys)-BSA]. Because it is TMG cap independent, the pathway of import of the U3 snRNP is formally similar to that of the U4 and U5 snRNPs (Fischer et al. 1991). Presumably, proteins of the U4 and U5 snRNPs are recognized by a cytosolic receptor protein before import. Although proteins of the U3 snRNP are also likely to be critical to import, the receptor would be expected to be different because no polypeptides are known to be shared between the U3 and the U4 or U5 snRNPs.

We have determined that the U3 snRNA requires a structural motif, an intact 3'-terminal stem of $5 \mathrm{bp}$, for both import and cap trimethylation. When a fragment of the U3 snRNA containing the 3 '-terminal 13 nucleotides, which includes the $3^{\prime}$-terminal stem, is injected into oocytes, it appears to be sufficient for import, although we interpret these results cautiously because the fragment is subject to severe degradation. A 3 '-terminal stem is conserved among U3 snRNAs from plants to mammals, although the sequences of the base-paired regions are not (Parker and Steitz 1987; Jeppesen et al. 1988). The sequences that comprise Box D and the 3'terminal stem are likely to be a protein-binding site based on RNase protection analyses of native human U3 snRNPs (Parker and Steitz 1987). However, because the only U3 sequence known to be required for binding of a known protein is an intact box $\mathrm{C}$ sequence for $\mathrm{Fb}$ association in vitro (Baserga et al. 1991), further characterization of U3 snRNP proteins is necessary to establish whether the stem is important for RNA-protein interactions or only as a structure required for import.

This is not the first instance in which an RNA structural motif plays an important role in production of intact snRNPs. A terminal stem domain of $4-6 \mathrm{bp}$ is required for accumulation of another nucleolar snRNA that binds $\mathrm{Fb}$, the yeast U14 snRNA ( $\mathrm{Li}$ and Fournier 1992). Our studies on the human U3 snRNA suggest that the presence of the $3^{\prime}$-terminal stem is required for biogenesis of the U3 snRNP; in contrast, the yeast U14 snRNA 3'-terminal stem seems to be crucial for RNA stability.

In addition, there are several lines of evidence that suggest that the bipartite signal for nuclear import (Sm proteins and TMG cap) of the U1 and U2 snRNAs functions only in the presence of the correct RNA structure. More specifically, all of the snRNAs studied so far with respect to their nuclear import possess stems at or near their $3^{\prime}$ ends. Results with human U1 and U2 snRNAs suggest that their $3^{\prime}$-terminal stems might be important for nuclear import (Neumann de Vegvar and Dahlberg 1990). In general, elongated human U1 and U2 snRNAs are not efficiently imported without prior $3^{\prime}$ end trimming. Surprisingly, two RNAs (hU2 +8 and sp-hU1 +15 ) are efficiently imported. Unlike the other elongated snRNAs, these RNAs can be folded so that they would have a base-paired stem at their $3^{\prime}$ ends. Xenopus U2 snRNAs that are elongated at their $3^{\prime}$ ends (Konings and Mattaj 1987) are not imported, although they do bind the Sm proteins. By computer analysis, these RNAs have a different structure than the wild type. However, deletion of a single nucleotide from the $3^{\prime}$ end of human U1 snRNA, which would maintain the $3^{\prime}$ stem, also curtails import, suggesting that for $\mathrm{U} 1$ and $\mathrm{U} 2$ the structural signal for transport is more complicated than the mere presence of a 3'-terminal stem (Neumann de Vegvar and Dahlberg 1990).

Kiss et al. (1991) have presented convincing evidence that the U3 snRNA in plants is transcribed by RNA polymerase III and does not possess a trimethyl cap structure. They argue that this conversion from synthesis by polymerase II to III probably occurred after the evolution of plants. It follows that the pathway for biogenesis of plant U3 must be different from what we have deduced here for mammalian U3 snRNA. Interestingly, when the plant $\mathrm{U} 3$ gene is manipulated so that it is transcribed by RNA polymerase II, although the U3 snRNA binds Fb and acquires a trimethylated cap structure, it does not become part of a larger complex that is thought to function in rRNA processing (Kiss et al. 1991). Clearly, therefore, the pathway of U3 snRNP biogenesis does affect its ability to be utilized correctly, and the alternate pathway for biogenesis evolved by mammalian cells is incapable of achieving functional U3 complexes in plants.

Unlike the spliceosomal snRNAs (U1, U2, U4, and U5), which are nucleoplasmic, the human U3 snRNA ultimately becomes localized in the nucleolus. It is not known whether the signals for nuclear import of the U3 snRNP and those for its targeting to the nucleolus are overlapping or discrete. Sequences necessary for nucleolar localization of the following proteins have been delineated: HSP70 (Munro and Pelham 1984; Dang and Lee 1989; Milarski and Morimoto 1989), the Tat and Rev proteins of human immunodeficiency virus (HIV) (Dang and Lee 1989; Cochrane et al. 1990), the Rex protein of human T-cell leukemia virus, type I (HTLV-I) (also called p27X-III; Siomi et al. 1988), and the NO38 protein (Peculis and Gall 1992). Only in the case of NO38 (Peculis and Gall 1992) has the sequence for nucleolar localization been shown to be nonoverlapping with the signal for nuclear localization. The truncated and mutated U3 snRNAs that we have constructed will be useful for determining the regions of U3 snRNA that are necessary for nucleolar localization.

\section{Materials and methods}

Reagents

Restriction enzymes and DNA-modifying enzymes were obtained from New England Biolabs, Pharmacia, and Boehringer 
Mannheim. Nucleotides and dinucleotides (GpppG and ApppG) were purchased from Pharmacia. Female Xenopus laevis specimens were obtained from Xenopus I. Oligonucleotides were synthesized on an Applied Biosystems oligonucleotide synthesizer by Dr. John Flory (Yale University School of Medicine, New Haven, CT).

\section{Antibodies}

$\alpha$ TMG antibodies (Krainer 1988) were obtained from Oncogene Science (Manhasset, NY). $\alpha \mathrm{Fb}$ antibodies (no. 1875) were obtained from patients with scleroderma and were the gift of Joe Craft (Yale University School of Medicine). $\alpha \mathrm{Fb}$ monoclonal antibody (Reimer et al. 1987) was a gift from Eng Tan and Michael Pollard (Scripps Clinic, La Jolla, CA). Anti-Sm antibodies were from the hybridoma cell line Y-12 (Lerner et al. 1981) and were prepared by Mei-Di Shu.

\section{snRNA constructs and mutagenesis}

The rat U3 gene (-375 U3D) was obtained from Rob Ach and Alan Weiner. It contains a clone of the rat U3D gene in pUC13 with -375 of the $5^{\prime}$-flanking region. This clone is transcribed at the same levels as the U3D gene with -538 of the $5^{\prime}$-flanking region (Ach and Weiner 1991; Stroke and Weiner 1985).

The human U3 cDNA cloned behind a T7 RNA polymerase promoter was constructed as described previously (Baserga et al. 1991). The U3 cDNA is cloned both into the pSP64 plasmid (Promega Biotech) and into M13 mpl8. The construction of the U3G159A mutation was described previously (Baserga et al. 1991). Site-directed mutagenesis was performed to create substitution/deletions at conserved boxes $B, C$, and $D(\Delta B, \Delta C, \Delta D)$ and in the $3^{\prime}$-terminal stem (Fig. 3; Zoller and Smith 1983; Kunkel et al. 1987). The following oligonucleotides were used: for $\triangle \mathrm{B}, 5^{\prime}$-GCCAGAAAGCCGGCAAAAAAAAAAGGAGAAAACGCTACC; for $\triangle \mathrm{C}, 5^{\prime}$-TACGGAGAGAAGAAGGGGGGGGGATGGCTGACGGCAGTTGC; for $\triangle \mathrm{D}, 5^{\prime}$-ACCACTTTTTTCGCGTTCTCTCCCTCTCACTCCC; for the stem mutation, 5' -CCCCGGGTACCGAGCTCCCGGGTGTCAGACCGCGTTCTCTCC; and for the stem mutation suppressor, 5' $-\mathrm{CG}^{-}$ CTACCTCTCTTCCTCCACCCTTTTCGGTGCTCTAC. All clones were sequenced in their entirety. RF M13 DNA was prepared according to standard procedures.

The U3 3'-end fragment clone was constructed using two overlapping oligonucleotides containing U3 nucleotides 71-101 and 198-217, as well as a T7 RNA polymerase promoter, EcoRI and HindIII restriction sites on the ends, an RsaI site at the end of the U3 RNA sequence, an extra G on the 5' end, and a stable tetraloop (Fig. 6A). The sequences of the oligonucleotides are 5'-AATTCTAATACGACTCACTATAGGAAAACCACGAGGAAGAGAGGTAGCGTTTTCTTCGGAGAACGCGGTCTGAGTGGTACCA and 5'-AGCTTGGTACCACTCAGACCGCGTTCTCCGAAGAAAACGCTACCTCTCTTCCTCGTGGTTTTCCTATAGTGAGTCGTATTAG. These oligonucleotides were cloned directly into plasmid pSp64 after kinasing and annealing.

pHU1 was originally obtained from Thoru Pederson (Patton et al. 1987) and contains a human U1 RNA under the control of an SP6 RNA polymerase promoter.

\section{Transcriptions}

U3 plasmid or RF DNA was linearized with RsaI for generation of full-length U3 transcripts or with BstUI, Fnu4HI, or DdeI for generation of truncated U3 transcripts. The U3 stem mutation and stem suppressor DNAs were linearized with SmaI. The U3
3 '-end fragment was linearized with $R s a \mathrm{I}$ and, upon transcription, yields an RNA of 56 nucleotides. The pHUl plasmid was linearized with $B a m H I$, which upon transcription gives a U1 RNA 25 nucleotides beyond the correct $3^{\prime}$ end. To produce U1 minus Sm, pHUl was cut with TaqI, giving a transcript of 115 nucleotides, ending before the Sm site. Transcriptions were performed with $1 \mu \mathrm{g}$ of DNA template in $40 \mathrm{~mm}$ Tris ( $\mathrm{pH} 7.5), 6 \mathrm{mM}$ $\mathrm{MgCl}_{2}, 2 \mathrm{~mm}$ spermidine, $40 \mathrm{mM}$ dithiothreitol, $250 \mu \mathrm{M}$ each cytidine triphosphate and guanosine triphosphate, $100 \mu \mathrm{M}$ each uridine triphosphate and adenosine triphosphate, $2 \mathrm{mM} \mathrm{GpppG}$ or ApppG dinucleotide, $40 \mu \mathrm{Ci}\left[\alpha-{ }^{32} \mathrm{P}\right]$ uridine triphosphate and $\left[\alpha-{ }^{32} \mathrm{P}\right]$ adenosine triphosphate (specific activity each of $3000 \mathrm{Ci} /$ mmole; $10 \mu \mathrm{Ci} / \mu \mathrm{l}$ ), 80 units of RNase inhibitor (Boehringer Mannheim), and 120 units of T7 or SP6 RNA polymerase (Pharmacia).

\section{Oocyte injections}

Injections of the rat -375 U3D gene into the nucleus of Xenopus oocytes were performed according to Ach and Weiner (1991).

When RNA was injected, $\sim 10$ fmoles $\left\{0.5 \times 10^{6} \mathrm{cpm} / \mu \mathrm{l}\right)$ of either ${ }^{32} \mathrm{P}$-labeled U1 or U3 RNA was injected into the vegetal pole of stage VI Xenopus oocytes. Oocytes were incubated at $18^{\circ} \mathrm{C}$ in Barth's modified saline (MBS) overnight or as indicated. Oocytes were dissected manually into nucleus and cytoplasm after transfer into ice-cold dissecting buffer [ $80 \%$ ethanol $/ 3 \%$ acetic acid (vol/vol); de la Pena and Zasloff 1987]. Twenty oocytes were injected for each RNA, half were harvested at 0 time, and half were harvested after incubation. For analysis of import and cap trimethylation, RNA was harvested according to Hamm et al. (1990). All of the RNA from each injection was analyzed on an $8 \%$ polyacrylamide gel.

When $\alpha \mathrm{Fb}$ monoclonal antibodies are injected, they are injected into the vegetal pole of stage VI oocytes $1 \mathrm{hr}$ before injection of in vitro-transcribed U3 snRNA. Approximately $50 \mathrm{nl}$ of purified $\alpha \mathrm{Fb}$ antibody is injected; the highest concentration of antibody used is $0.8 / \mathrm{mg} / \mathrm{ml}$. Analysis of nuclear import proceeds as described above.

\section{Enucleation}

The enucleation of oocytes was performed using the procedure of Ford and Gurdon (1977). Oocytes were inspected for resealing, transferred to MBS buffer, and allowed to incubate for $3 \mathrm{hr}$ before use.

\section{Immunoprecipitations}

RNAs were immunoprecipitated either from purified RNA ( $\alpha$ TMG) or from Xenopus oocyte extracts ( $\alpha \mathrm{Fb}$ autoantibodies). RNA was purifed from 10 oocytes at the indicated time points according to Hamm et al. (1990). Extracts were prepared from 10 oocytes at the indicated time points by homogenization in NET-2 buffer $(150 \mathrm{~mm} \mathrm{NaCl}, 50 \mathrm{~mm}$ Tris at $\mathrm{pH} 7.5,0.05 \%$ NP-40), followed by a 10-min microcentrifuge spin. Except for the experiment in Figure 1C, equal amounts of radioactive RNA, as measured by a scintillation counter, were used for each set of precipitations. For Figure $1 \mathrm{C}$, equal numbers of injected oocytes were used, and a 0 -hr time point (background binding) was included that reflects the amount of RNA injected. Two microliters of $\alpha \mathrm{TMG}$ and $10 \mu \mathrm{l}$ of $\alpha \mathrm{Fb}$ antibody were used in the respective precipitations. Immunoprecipitations were performed as described in Steitz (1988). 


\section{Acknowledgments}

We thank Joe Craft, Eng Tan, and Michael Pollard for generous gifts of $\alpha \mathrm{Fb}$ antibodies; Rob Ach and Alan Weiner for the gift of the rat U3 gene; James Fischer for his support; Joy Hirsch for her help with statistical analyses; and Michele Caizergues-Ferrer and David Goldfarb for communication of results before publication. We thank Jon Izant for encouraging us to pursue these studies, for helpful discussions, and for Xenopus and facilities for microinjection. We also thank the members of the Izant laboratory for their understanding and cooperation. We thank Brenda Peculis for critical reading of the manuscript. We are grateful to Joan Steitz for her continued support, guidance, and inspiration and for her help in preparation of this manuscript. This work was supported in part by grant GM26154 from the National Institutes of Health to J.A. Steitz. S.J.B. is a fellow of the Leukemia Society of America.

The publication costs of this article were defrayed in part by payment of page charges. This article must therefore be hereby marked "advertisement" in accordance with 18 USC section 1734 solely to indicate this fact.

\section{References}

Ach, R.A. and A.M. Weiner. 1991. Cooperation between CCAAT and octamer motifs in the distal sequence element of the rat U3 small nucleolar RNA promoter. Nucleic Acids Res. 19: 4209-4218.

Andersen, J. and G.W. Zieve. 1991. Assembly and intracellular transport of snRNP particles. BioEssays 13: 57-63.

Baserga, S.J., X.W. Yang, and J.A. Steitz. 1991. An intact Box C sequence is required for binding of fibrillarin, the protein common to the major family of nucleolar snRNPs. EMBO $\%$. 10: 2645-2651.

Caizergues-Ferrer, M., C. Mathieu, P. Mariottini, F. Amalric, and F. Amaldi. 1991. Developmental expression of fibrillarin and U3 snRNA in Xenopus laevis. Development 112: 317326.

Cochrane, A.W., A. Perkins, and C.A. Rosen. 1990. Identification of sequences important in the nucleolar localization of human immunodeficiency virus rev: Relevance of nucleolar localization to function. J. Virol. 64: 881-885.

Dahlberg, J.E. and E. Lund. 1988. The genes and transcription of the major small nuclear RNAs. In Small nuclear ribonucleoprotein particles (ed. M.L. Birnstiel), pp. 38-70. SpringerVerlag, Berlin, Germany.

Dang, C.V. and W.M.F. Lee. 1989. Nuclear and nucleolar targeting sequences of c-erb-A, c-myb, N-myc, p53, HSP70 and HIV tat proteins. J. Biol. Chem. 264: 18019-18023.

Das, G., D. Henning, D. Wright, and R. Reddy. 1988. Upstream regulatory elements are necessary and sufficient for transcription of a U6 RNA gene by RNA polymerase III. EMBO J. 7: 503-512.

de la Pena, P. and M. Zasloff. 1987. Enhancement of mRNA nuclear transport by promoter elements. Cell 50: 613-619.

De Robertis, E.M., S. Lienhard, and R.F. Parisot. 1982. Intracellular transport of microinjected $5 S$ and small nuclear RNAs. Nature 295: 572-576.

Dingwall, C. 1991. If the cap fits. . . Curr. Biol. 1: 65-66.

Eliceiri, G.L. 1974. Short-lived, small RNAs in the cytoplasm of HeLa cells. Cell 3: 11-14.

Eliceiri, G.L. and M.S. Sayavedra. 1976. Small RNAs in the nucleus and cytoplasm of HeLa cells. Biochem. Biophys. Res. Commun. 72: 507-512.

Feeney, R.J., R.A. Sauterer, J.L. Feeney, and G.W. Zieve. 1989. Cytoplasmic assembly and nuclear accumulation of mature
snRNP particles. J. Biol. Chem. 264: 5776-5783.

Fischer, U. and R. Lührmann. 1990. An essential signaling role for the $\mathrm{m}_{3} \mathrm{G}$ cap in the transport of U1 snRNP to the nucleus. Science 249: 786-790.

Fischer, U., E. Darzynkiewicz, S.M. Tahara, N.A. Dathan, R. Lührmann, and I.W. Mattaj. 1991. Diversity in the signals required for nuclear accumulation of $U$ snRNPs and variety in the pathways of nuclear import. J. Cell Biol. 113: 705-713.

Forbes, D.J., T.B. Kornberg, and M.W. Kirschner. 1983. Small nuclear RNA transcription and ribonucleoprotein assembly in early Xenopus development. I. Cell. Biol. 97: 62-72.

Ford, C.C. and J.B. Gurdon. 1977. A method for enucleating oocytes of Xenopus laevis. I. Embryol. Exp. Morphol. 37: 203-209.

Goldfarb, D. and N. Michaud. 1991. Pathways for the nuclear transport of proteins and RNAs. Trends Cell Biol. 1: 20-24.

Gurney, T. Jr. and G.L. Eliceiri. 1980. Intracellular distribution of low molecular weight RNA species in HeLa cells. $/$. Cell Biol. 87: 398-403.

Hamm, J. and I.W. Mattaj. 1989. An abundant U6 snRNP found in germ cells and embryos of Xenopus laevis. EMBO $J$. 8: $4179-4187$.

- 1990. Monomethylated cap structures facilitate RNA export from the nucleus. Cell 63: 109-118.

Hamm, J., E. Darzynkiewicz, S.M. Tahara, and I.W. Mattaj. 1990. The trimethylguanosine cap structure of U1 snRNA is a component of a bipartite nuclear targeting signal. Cell 62: $569-577$.

Jeppesen, C., B. Stebbins-Boaz, and S.A. Gerbi. 1988. Nucleotide sequence determination and secondary structure of Xenopus U3 snRNA. Nucleic Acids Res. 5: 2127-2148.

Kass, S., D. Tyc, J.A. Steitz, and B. Sollner-Webb. 1990. The U3 small nucleolar ribonucleoprotein functions in the first step of preribosomal RNA processing. Cell 60: 897-908.

Kiss, T., C. Marshallsay, and W. Filipowicz. 1991. Alteration of the RNA polymerase specificity of snRNA genes during evolution and in vitro. Cell 65:517-526.

Konings, D.A.M. and I.W. Mattaj. 1987. Mutant U2 snRNAs of Xenopus which can form altered higher order RNA structure are unable to enter the nucleus. Exp. Cell Res. 172: 329-339.

Krainer, A.R. 1988. Pre-mRNA splicing by complementation with purified human U1, U2, U4/U6 and U5 snRNPs. Nucleic Acids Res. 16: 9415-9429.

Kunkel, G.R., R.L. Maser, J.P. Calvet, and T. Pederson. 1986. U6 small nuclear RNA is transcribed by RNA polymerase III. Proc. Natl. Acad. Sci. 83: 8575-8579.

Kunkel, T.A., J.D. Roberts, and R.A. Zakour. 1987. Rapid and efficient site-specific mutagenesis without phenotypic expression. Methods Enzymol. 154: 367-382.

Lamond, A.I. 1990. The trimethylguanosine cap is a nuclear targeting signal for snRNPs. Trends Biochem. Sci. 15: 451452.

Lerner, E.A., M.R. Lerner, C.A. Janeway Ir., and J.A. Steitz. 1981. Monoclonal antibodies to nucleic acid-containing cellular constituents: Probes for molecular biology and autoimmune disease. Proc. Natl. Acad. Sci. 78: 2737-2741.

Li, H.V. and M.J. Fournier. 1992. U14 function in Saccharomyces cerevisiae can be provided by large deletion variants of yeast U14 and hybrid mouse : yeast U14 RNAs. EMBO $\%$. 11: $683-689$.

Mattaj, I.W. 1986. Cap trimethylation of U snRNA is cytoplasmic and dependent on $\mathrm{U}$ snRNP protein binding. Cell 46: 905-911.

Mattaj, I.W. and E.M. DeRobertis. 1985. Nuclear segregation of U2 snRNA requires binding of specific snRNA proteins. Cell 40: $111-118$. 
Michaud, N. and D. Goldfarb. 1992. Microinjected U snRNPs are imported to oocyte nuclei via the nuclear pore complex by at least three distinguishable targeting pathways. $J$. Cell Biol. 116: 851-861.

Milarski, K.L. and R.I. Morimoto. 1989. Mutational analysis of the human HSP70 protein : distinct domains for nucleolar localization and adenosine triphosphate binding. J. Cell Biol. 109: 1947-1962.

Munro, S. and H.R.B. Pelham. 1984. Use of peptide tagging to detect proteins expressed from cloned genes: Deletion mapping functional domains of Drosophila HSP70. EMBO $J$. 3: 3087-3093.

Neuman de Vegvar, H.E. and J.E. Dahlberg. 1990. Nucleocytoplasmic transport and processing of small nuclear RNA precursors. Mol. Cell. Biol. 10: 3365-3375.

Nigg, E.A., P.A. Baeuerle, and R. Lührmann. 1991. Nuclear import-export: In search of signals and mechanisms. Cell 66: $15-22$.

Parker, K.A. and J.A. Steitz. 1987. Structural analyses of the human U3 ribonucleoprotein particle reveal a conserved sequence available for base pairing with pre-rRNA. Mol. Cell. Biol. 7: 2899-2913.

Parry, H.D., D. Scherly, and I.W. Mattaj. 1989. "Snurpogenesis": The transcription and assembly of U snRNP components. Trends Biochem. Sci. 14: 15-19.

Patton, J.R., R.J. Patterson, and T. Pederson. 1987. Reconstitution of the U1 small nuclear ribonucleoprotein particle. Mol. Cell. Biol. 7: 4030-4037.

Peculis, B.A. and J.G. Gall. 1992. Localization of the nucleolar protein NO38 and amphibian oocytes. J. Cell Biol. 116: 114.

Porter, G.L., P.J. Brennwald, K.A. Holm, and J.A. Wise. 1988. The sequence of U3 from Schizosaccharomyces pombe suggests structural divergence of this snRNA between metazoans and unicellular eukaryotes. Nucleic Acids Res. 16: 10131-10152.

Reddy, R. and H. Busch. 1988. Small nuclear RNAs: RNA sequences, structure and modifications. In Small nuclear ribonucleoprotein particles (ed. M.L. Birnstiel), pp. 1-37. Springer-Verlag, Berlin, Germany.

Reimer, G., K.M. Pollard, C.A. Penning, R.L. Ochs, M.A. Lischwe, H. Busch, and E.M. Tan. 1987. Monoclonal antibody from a (New Zealand black $\times$ New Zealand white) $F 1$ mouse and some human scleroderma sera target an $\mathrm{Mr} 34,000 \mathrm{nu}-$ cleolar protein of the U3 RNP particle. Arthritis Rheum. 30: $793-800$.

Savino, R. and S.A. Gerbi. 1990. In vivo disruption of Xenopus U3 snRNA affects ribosomal RNA processing. EMBO $I$. 9: 2299-2308.

Singh, R., S. Gupta, and R. Reddy. 1990. Capping of mammalian U6 small nuclear RNA in vitro is directed by a conserved stem-loop and AUAUAC sequence: Conversion of a noncapped RNA into a capped RNA. Mol. Cell. Biol. 10: 939946.

Siomi, H., H. Shida, S.H. Nam, T. Nosaka, M. Maki, and M. Hatanaka. 1988. Sequence requirements for nucleolar localization of human $\mathrm{T}$ cell leukemia virus type I $\mathrm{pX}$ protein, which regulates viral RNA processing. Cell 55: 197-209.

Steitz, J.A. 1988. Immunoprecipitation of ribonucleoproteins using autoantibodies. Methods Enzymol. 180: 468-481.

Stroke, I.L. and A.M. Weiner. 1985. Genes and pseudogenes for rat U3A and U3B small nuclear RNA. J. Mol. Biol. 184: 183193.

Tollervey, D., H. Lehtonen, M. Carmo-Fonseca, and E.C. Hurt. 1991. The small nucleolar RNP protein NOPl (fibrillarin) is required for pre-rRNA processing in yeast. $E M B O J$. 10: 573
583.

Tyc, K. and J.A. Steitz. 1989. U3, U8 and U13 comprise a new class of mammalian snRNPs localized in the cell nucleolus. EMBO I. 8: 3113-3119.

Vankan, P., C. McGuigan, and I.W. Mattaj. 1990. Domains of U4 and U6 snRNAs required for snRNP assembly and splicing complementation in Xenopus oocytes. EMBO I. 9: 33973404.

Zeller, R., T. Nyffenegger, and E.M. DeRobertis. 1983. Nucleocytoplasmic distribution of snRNPs and stockpiled snRNAbinding proteins during oogenesis and early development in Xenopus laevis. Cell 32: 425-434.

Zieve, G.W. and S. Penman. 1976. Small RNA species of the HeLa cell: Metabolism and subcellular localization. Cell 8: 19-31.

Zieve, G.W., R.A. Sauterer, and R.J. Feeney. 1988. Newly synthesized small nuclear RNAs appear transiently in the cytoplasm. I. Mol. Biol. 199: 259-267.

Zoller, M.J. and M. Smith. 1983. Oligonucleotide-directed mutagenesis of DNA fragments cloned into M13 vectors. Methods Enzymol. 100: 468-500. 


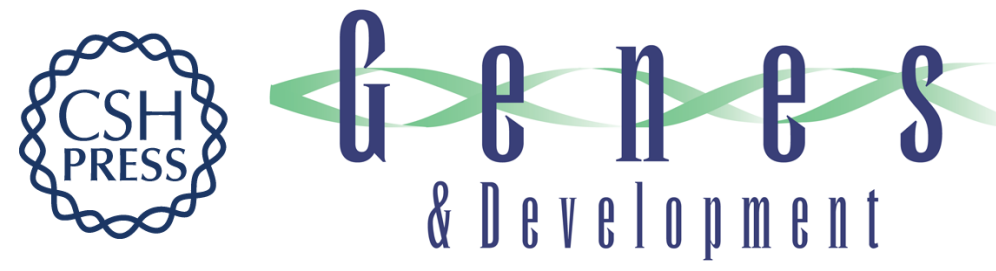

\section{Distinct molecular signals for nuclear import of the nucleolar snRNA, U3.}

S J Baserga, M Gilmore-Hebert and X W Yang

Genes Dev. 1992, 6:

Access the most recent version at doi:10.1101/gad.6.6.1120

References This article cites 57 articles, 17 of which can be accessed free at: http://genesdev.cshlp.org/content/6/6/1120.full.html\#ref-list-1

License

Email Alerting

Service

Receive free email alerts when new articles cite this article - sign up in the box at the top right corner of the article or click here.

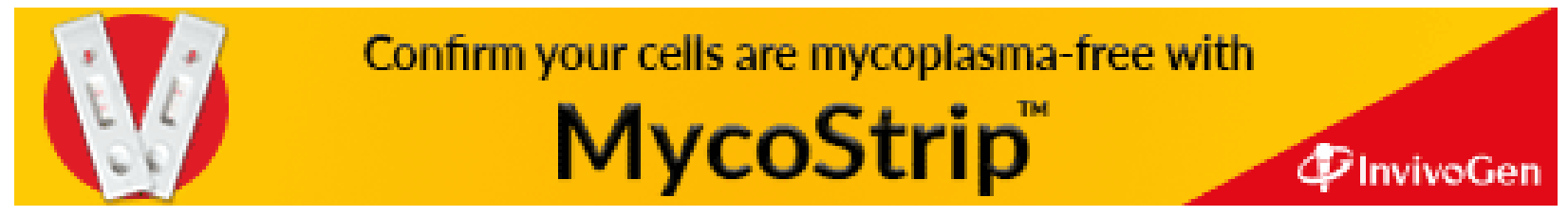

